\title{
BMJ Open Cholesterol and triglyceride levels in midlife and risk of heart failure in women, a longitudinal study: the prospective population study of women in Gothenburg
}

To cite: Halldin A-K, Lissner L, Lernfelt B, et al. Cholesterol and triglyceride levels in midlife and risk of heart failure in women, a longitudinal study: the prospective population study of women in Gothenburg. BMJ Open 2020;10:e036709. doi:10.1136/ bmjopen-2019-036709

- Prepublication history for this paper is available online. To view these files, please visit the journal online (http://dx.doi. org/10.1136/bmjopen-2019036709).

Received 28 December 2019 Revised 02 May 2020 Accepted 05 May 2020

Check for updates

(C) Author(s) (or their employer(s)) 2020. Re-use permitted under CC BY-NC. No commercial re-use. See rights and permissions. Published by BMJ.

For numbered affiliations see end of article.

Correspondence to

Dr Anna-Karin Halldin;

anna-karin.halldin@vgregion.se

\section{ABSTRACT}

Objective To examine the association between triglycerides and cholesterol serum values and risk of developing heart failure in women.

Design Longitudinal observational study of four cohorts 50-year-old women examined in 1968-1969, 1980-1981, 1992-1993 and 2004-2005, and followed until 2012. Striglycerides and s-cholesterol were measured at baseline and heart failure morbidity and mortality data collected from 1980 to 2012.

Setting Prospective population study Gothenburg, Sweden. Primary care.

Participants 1143 women 50 year old without history of heart failure or myocardial infarction.

Main outcome measure Association among striglycerides, s-cholesterol and heart failure expressed as HR for heart failure, adjusted for smoking, body mass index (BMI), physical activity and age.

Results For 50-year-old women examined in 1968-1969, there was an independent association between level of s-triglycerides and heart failure and a significantly higher risk of developing heart failure (HR 1.8; $\mathrm{Cl} 1.16$ to 2.80, for each increment of $1.0 \mathrm{mmol} / \mathrm{L}$ in s-triglycerides), adjusted for smoking, BMI, physical activity and age. There was no significant association between s-cholesterol and risk of heart failure (HR 0.9 ; $\mathrm{Cl} 0.77$ to 1.15). In the cohorts of 50-year-old women examined in 1980 and 1992, there were no significant associations between neither s-triglycerides or s-cholesterol and the risk of heart failure. In the pooled analyses of the cohorts examined in 1968, 1980 and 1992, a significantly increased risk of heart failure was found (HR 1.49; $\mathrm{Cl} 1.10$ to 2.03) for s-triglycerides independently, but not for s-cholesterol. None of the 50-year-old women examined in 2004-2005 developed heart failure by 2012 and were excluded from further analyses.

Conclusions High levels of s-triglycerides but not scholesterol may be a risk marker for later development of heart failure in 50-year-old women.

\section{INTRODUCTION}

Heart failure is a progressive severe condition that gradually reduces the physical capacity and affects the cognitive capability of the
Strengths and limitations of this study

- This study has a high participation rate.

- This study has a high representativeness of women in the study area.

- There was a long follow-up time, 20-44 years.

- There was a fairly small number of women in each cohort.

- Analyses of lipids such as high-density lipoprotein, low-density lipoprotein or apolipoprotein were not available at the time.

patient. ${ }^{1}$ Heart failure is associated with a considerable amount of personal suffering and a great burden on hospital care and the economy. ${ }^{2} 3$ The prognosis is found to be worse than for some of the most common types of cancers. ${ }^{4}$ The overall prevalence of heart failure in developed countries is around $2 \% .^{5}$ In Sweden, the estimated prevalence was $2.2 \%$ in $2010 .^{6}$ The American Heart Association predicts an increase in heart failure prevalence from $2.42 \%$ in 2010 to $2.97 \%$ in $2030 .^{7}$ The prevalence increases with age to about $8.4 \%$ for those aged 75 years or older. ${ }^{8}$

There are several risk factors for heart failure, and they differ somewhat between men and women. Heart failure is more common among men than among women up to the age of 80 years. Heart failure with reduced ejection fraction as a result of ischaemic heart disease is more prevalent among men, while heart failure with preserved ejection fraction related to hypertensive heart disease is the most prevalent form of heart failure in elderly women. Important comorbidities in women are diabetes, anaemia and thyroid diseases. ${ }^{9}$ Smoking, obesity and a sedentary life style have also been shown to be mutually independent risk factors for future heart failure in women. ${ }^{1011}$ High levels 
of serum high-density lipoprotein cholesterol (HDLcholesterol) and triglycerides have been associated with lower mortality in patients with already established symptomatic heart failure, ${ }^{12}$ and elevated non-HDL-cholesterol and decreased HDL-cholesterol have been associated with an increased risk of future heart failure. ${ }^{13}$ Increased apolipoprotein B/apolipoprotein A-1 (apo B/apo A-1) ratio and the metabolic syndrome have also been shown to be independent risk factors for heart failure in men. ${ }^{145}$

Most studies on lipids and heart failure have not focused on women. Thus, the role of serum cholesterol and triglycerides as a possible risk marker for future heart failure in women has not been thoroughly investigated. One study showed that among the lipid components, the apo B/apo A-1 ratio and triglycerides were the strongest risk factors for heart failure. In men, the apo B/apo A-1 ratio was the best predictor for heart failure, whereas in women triglycerides were slightly better predictors. ${ }^{16}$ The study did not take into consideration other important factors such as body weight, alcohol use and smoking.

We therefore found it important to focus on cholesterol and triglycerides and their significance in the development of heart failure in women.

\section{AIM}

The aim of this study was to examine the role of serum triglycerides and serum cholesterol on the risk of developing heart failure in population-based cohorts of 50-year-old women.

\section{METHODS}

\section{Study population}

The study population includes 1145 50-year-old women, originating from the Prospective Population Study of Women in Gothenburg (PPSWG). The participants were selected from the Swedish Population Register based on birth dates and shown to be representative of the female population in Gothenburg.

The PPSWG was initiated in 1968-1969 with a crosssectional examination of 1462 women aged 38, 46, 50, 54 and 60 years. Ninety-one per cent of the initially sampled
436 50-year-old women participated $(\mathrm{n}=398)$. All the women were followed longitudinally and the examinations were conducted according to the same protocol at every re-examination. ${ }^{17}$

In 1980-1981, a follow-up examination was performed. To ensure representativeness, women born 1930 outside Gothenburg, but who had moved into the study area and who fulfilled the inclusion criteria, were invited to the examination together with women examined in 19681969 at the age of 38 years. The examination included 355 women born 1930 and representative of the 50-year-old female population. Participation rate in 1980-1981 was $83 \% .^{18}$

The next follow-up was conducted in 1992-1993. Ninety-nine women participated at the age of 50 years. Out of 122 women examined in 1980-1981 at age 38 years, 93 were re-examined at age 50 years (participation rate $76 \%$ ). To guarantee representativeness also in this examination, women who had moved into Gothenburg and fulfilled the inclusion criteria were invited. Six women were newly included at age $50 .^{19}$

In 2004-2005, a new follow-up was performed. At this examination, women who had previously participated in the PPSWG were invited together with a new sample of women aged 50 years who lived in Gothenburg. In total, 503 50-year-old women were invited. Two hundred and ninety-three women participated, resulting in a participation rate of $58 \%$. The new sample was recruited from the Revenue Office Register based on birth dates to make it representative, and women who had previously participated in the PPSWG were invited even though they were living outside Gothenburg. ${ }^{20}$

The number of participants, participation rates and the duration of the follow-up period are shown in table 1 .

In order to perform the examinations at the time of the girl's age +6 months, the examination period started in the autumn of the examination year and extended to late spring of the following year. For simplification purposes, examination year 1968-1969 is indicated as 1968, 19801981 as 1980 and so on.

Table 1 Year of birth date and age (years), numbers of participants ( $\mathrm{n}$ ) and participation rates (\%) in 1968-1969, 1980-1981, 1992-1993 and 2004-2005

\begin{tabular}{|c|c|c|c|c|c|c|c|}
\hline $\begin{array}{l}\text { Year of examination } \\
\text { Year of birth }\end{array}$ & \multicolumn{2}{|c|}{ 1968-1969 } & \multicolumn{2}{|c|}{$1980-1981$} & \multicolumn{2}{|c|}{$1992-1993$} & $\begin{array}{l}\text { 2004-2005 } \\
1954\end{array}$ \\
\hline Age & 50 & 38 & 50 & 38 & 50 & 38 & 50 \\
\hline Participation rate (\%) & $91^{*}$ & & $83+$ & & $76 \ddagger$ & & $58 \S$ \\
\hline Follow-up (years) & 44 & & 32 & & 20 & & 8 \\
\hline
\end{tabular}

*Of the 436 women initially sampled at age 50 years old.

†Of the 372 women born in 1930 who participated in the examination 1968-1969.

¥Of the 122 women born in 1942 who participated in the examination 1980-1981.

§Of the 503 women invited in 2004-2005. 


\section{Methodology}

All the women underwent the same investigations at all the follow-up examinations. The examinations contained a multidisciplinary investigation including registration of socioeconomic status based on the years of education, marital status and occupation of the woman/husband according to Carlsson's occupational grouping system. ${ }^{21}$ Information on lifestyle-related measures such as smoking habits, drinking habits and level of physical activity was registered. A general and gynaecological medical history, information on medication consumption was also registered; family history of diseases and life satisfaction assessments were collected.

Physical examinations were conducted by a nurse and a physician according to the same protocol at all examinations, including body weight, body height, calculation of body mass index (BMI, weight in kilograms divided by height in metres squared), waist circumference, hip circumference, waist-hip ratio (WHR) and blood pressure measurements. Using a balance scale, body weight was measured to the nearest $0.1 \mathrm{~kg}$. Body height was measured without shoes, in metres to the nearest $0.5 \mathrm{~cm}$. Waist circumference was measured by using a steel tape midway between the lowest rib and the iliac crest and estimated to the nearest $0.5 \mathrm{~cm}$, and hip circumference was measured at the level of the widest circumference over greater trochanters. In the morning, blood samples were drawn, and a urinary sample was collected. The women were instructed not to eat during the preceding night but were allowed to drink water. Levels of total s-cholesterol, s-triglycerides and b-glucose were analysed according to standard methods of the laboratory of the Sahlgrenska University Hospital, Gothenburg.

Systolic and diastolic blood pressure was measured in the sitting position after $5 \mathrm{~min}$ of rest, to the nearest $2 \mathrm{~mm}$ $\mathrm{Hg}$, using a mercury manometer, cuff width $12 \mathrm{~cm}$. A standard 12-lead ECG was taken.

\section{Definition of risk factors}

Socioeconomic position was classified into three groups, low, medium and high, according to Carlsson's standard occupations grouping system. ${ }^{21}$

Physical activity was assessed as leisure time physical activity, classified as not active (inactive or almost inactive) and active (at least 4 hours/week gardening, running, dancing, playing golf, tennis or similar activities during the last year or regular intense training several times per week), according to the validated Saltin-Grimby physical activity level scale. ${ }^{22}$

Women were classified according to their smoking habits as smokers (women who smoked more than one cigarette per day or had stopped smoking during the previous year) and non-smokers (women who had stopped smoking more than a year before examination and women who had never smoked).

Normal weight was classified as BMI $<25$. Overweight was classified as $25<\mathrm{BMI}<30$ and obesity was classified as $\mathrm{BMI} \geq 30$, in accordance with WHO classification.

\section{Ascertainment of diagnoses}

The diagnoses were classified according to the International Classification of Diseases (ICD), 9th revision (ICD-9) and from 1997, 10th revision (ICD-10). Heart failure was defined as ICD-9 428 A, B or X or ICD-10 I50.

\section{Follow-up data}

Hospital care diagnoses of heart failure were collected continually from the Swedish Hospital Discharge Registry, available since 1980, containing data about all discharge diagnoses from Swedish hospitals. The data collection period was from 1 January 1980 to 31 December 2012. Mortality data were collected from the Swedish National Board of Health and Welfare register of causes of death up to 31 December 2012. Ingelsson et al proved that, according to the European Society of Cardiology definition of heart failure, the accuracy of heart failure as a primary discharge diagnosis from Swedish hospital was $82 \%-95 \% .{ }^{23}$

Serum triglycerides and serum cholesterol were measured at baseline between 1968 and 2004. The cardiovascular disease risk time was calculated from the day the diagnosis was registered, and the longest follow-up time was 44 years.

\section{Statistical analyses}

There were four population-based cohorts of women aged 50 years, born in 1918, 1930, 1942 and 1954 and examined in 1968, 1980, 1992 and 2004, respectively. Only women without a history of heart failure were included in the analyses. Two women in the 1954 cohort developed heart failure before the age of 50 , and 18 women were diagnosed with myocardial infarction prior to the heart failure diagnosis. These 20 women were therefore excluded from further analyses.

Differences between groups concerning descriptive data were analysed by t-test for continuous variables and by Pearson's $\chi^{2}$ test for categorical variables. Incidence rate was calculated as risk of heart failure per 1000 person years at risk. The associations between heart failure and serum triglycerides and serum cholesterol as continuous variables were tested in Cox regression models, taking into consideration the time to receive a heart failure diagnosis. Descriptive statistics included number of cases, number of events, time at risk, incidence rate (risk per 1000 years), relative risk and mean risk time for each cohort and for the total number of participants (table 2).

In multivariable models, we controlled for age, BMI, smoking and physical activity. Main outcome measure was HR for heart failure and significance level was set at $\mathrm{p}<0.05$.

All statistical analyses were made by using SAS.

\section{Patient and public involvement}

It was not possible to involve patients or the public in the design, or conduct, or reporting, or dissemination plans of our research. 
Table 2 Number of cases, number of events, time at risk, incidence rate (risk per 1000 years), mean risk time for each cohort as well as for the total number of participants

\begin{tabular}{lclllllll}
\hline Year of birth & $\begin{array}{l}\text { Number of } \\
\text { women }\end{array}$ & $\begin{array}{l}\text { Number of } \\
\text { events }\end{array}$ & $\begin{array}{l}\text { Proportion } \\
\text { of events } \\
\text { (\%) }\end{array}$ & $\begin{array}{l}\text { Time at risk Risk per } \\
\text { years }\end{array}$ & $\begin{array}{l}\text { 1000 years } \\
\text { Cl (95\%) }\end{array}$ & $\begin{array}{l}\text { Mean risk } \\
\text { time }\end{array}$ & P values \\
\hline 1918 & 398 & 109 & 27.4 & 12483 & 8.7 & Reference & 31.4 & $<0.001$ \\
1930 & 355 & 42 & 11.8 & 9713 & 4.3 & 0.34 to 0.71 & 27.4 & $<0.001$ \\
1942 & 99 & 4 & 4.0 & 1877 & 2.1 & 0.07 to 0.64 & 19.0 & 0.001 \\
1954 & 291 & 0 & 0.0 & 2296 & 0.0 & 0.00 to 0.15 & 7.9 & $<0.001$ \\
\hline Total & 1143 & 155 & 5.9 & & & & & \\
\hline
\end{tabular}

\section{RESULTS}

The study included 1143 women examined at age 50.6 years and followed longitudinally. There was no difference in age between the different cohorts. During the follow-up period, 155 women were diagnosed with heart failure. In the cohort examined in 1968 and followed to the age of 94, 109 women developed heart failure. In the cohort examined in 1980 and followed to the age of 82, 42 women developed heart failure. Four of the 99 women examined in 1992 were diagnosed with heart failure. In the latest cohort examined in 2004, no women were diagnosed with heart failure. This cohort was therefore not included in the final analyses. Table 3 shows risk factor characteristics for the four cohorts.

Women in the oldest cohort had slightly higher systolic blood pressure. More women smoked in the cohort examined in 1980 compared with the other cohorts. Serum cholesterol and serum triglycerides were higher in the oldest cohort compared with the later born cohorts, whereas BMI did not significantly differ between the cohorts. Blood glucose and WHR were higher in the youngest cohort. More women in the examination 1968 and in the examination 2004 were physically active compared with women in the cohorts examined in 1980 and 1992. There were more women in the oldest cohort belonging to socioeconomic position level III, compared with the younger cohorts. When all three cohorts examined in 1968, 1980 and 1992 were analysed together, we found a significantly increased risk of heart failure (HR 1.49; CI 1.10 to 2.03) for serum triglycerides independently, but not for serum cholesterol, adjusted for smoking and BMI, physical activity and age. In the oldest

Table 3 Risk factor characteristics for 50-year-old women in the Prospective Population Study of Women in Gothenburg born in $1918,1930,1942$ and 1954

\begin{tabular}{|c|c|c|c|c|c|}
\hline & 1918 & 1930 & 1942 & 1954 & \\
\hline Year of birth & $\begin{array}{l}\mathrm{N}=398 \\
\text { Mean (SD) }\end{array}$ & $\begin{array}{l}\mathrm{N}=355 \\
\text { Mean (SD) }\end{array}$ & $\begin{array}{l}\mathrm{N}=99 \\
\text { Mean (SD) }\end{array}$ & $\begin{array}{l}\mathrm{N}=291 \\
\text { Mean (SD) }\end{array}$ & $P$ values \\
\hline $\mathrm{SBP}(\mathrm{mm} \mathrm{Hg})$ & $138(21.8)$ & $135(20.6)$ & $134(20.8)$ & $128(17.0)$ & $<0.001^{*}$ \\
\hline WHR $(\mathrm{cm} / \mathrm{cm})$ & $0.75(0.05)$ & $0.81(0.07)$ & $0.81(0.07)$ & $0.83(0.07)$ & $<0.001^{*}$ \\
\hline 1 & $48(12.5)$ & $30(9.9)$ & $8(8.2)$ & $96(33.8)$ & $<0.001 \ddagger$ \\
\hline II & $165(42.9)$ & $156(51.3)$ & $58(59.8)$ & $97(34.2)$ & \\
\hline III & $172(44.7)$ & $118(38.8)$ & $31(32.0)$ & $91(32.0)$ & \\
\hline Smoking n (\%) & $148(37.2)$ & $145(40.8)$ & 34 (34.3) & 67 (23.9) & $<0.001 \ddagger$ \\
\hline Serum triglycerides (mmol/L) & $1.3(0.58)$ & $1.2(0.58)$ & $1.2(0.60)$ & $1.0(0.54)$ & $<0.001^{\star}$ \\
\hline
\end{tabular}

$\mathrm{P}<0.05$ indicates significant difference between cohorts.

${ }^{*}$ Test of linear association.

†SEP=socioeconomic position level I-II-III.

$\ddagger \chi^{2}$ test

$\S$ Phys. Act=physically active $\geq 4$ hours/week.

BMI, body mass index; SBP, systolic blood pressure; WHR, waist-hip ratio. 
Table 4 Serum triglycerides (S-Tg) and serum cholesterol (S-Chol) as continuous variables and risk of heart failure in women in the cohorts born in 1918, 1930, 1942 and 1954

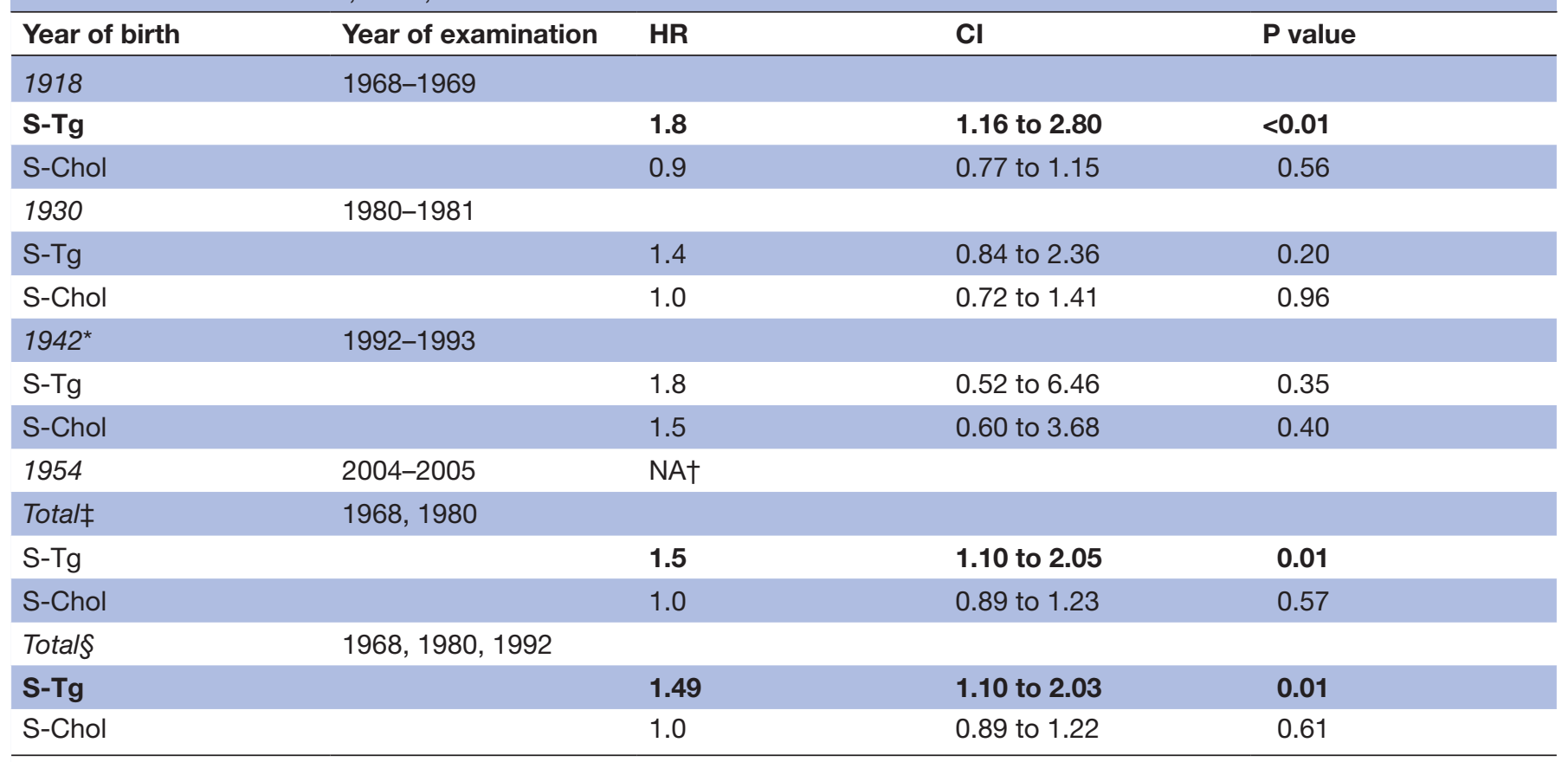

Adjusted for age, body mass index, smoking and physical activity. Bold figures statistically significant, $p<0.05$.

*Only four events.

†Zero events.

¥Combined analyses for the cohorts examined in 1968-1969 and 1980-1981 together.

§Combined analyses of the cohorts examined in 1968-1969, 1980-1981 and 1992-1993 together.

NA, not applicable.

cohort, for example, women 50 years old in the examination 1968-1969, analyses of serum triglycerides as a continuous variable, adjusted for smoking, BMI, physical activity and age, showed an independent association between the level of serum triglycerides and heart failure and a significantly higher risk of developing heart failure (HR 1.8; CI 1.16 to 2.80, for each increment of $1.0 \mathrm{mmol} / \mathrm{L}$ of serum triglycerides), whereas there was no significant association between serum cholesterol and the risk of heart failure (HR 0.9; CI 0.77 to 1.15 ). In the cohort of 50-year-old women examined in 1980 and 1992, there was no significant association between either serum triglycerides or serum cholesterol, adjusted for smoking and BMI, physical activity and age, on the risk of heart failure (table 4).

Kaplan-Meier survival plots for the examinations 1968 and 1980 showed estimated higher mortality over time in women with serum triglycerides $>2.0 \mathrm{mmol} / \mathrm{L}$, which was not seen in women with serum cholesterol $>6.8 \mathrm{mmol} / \mathrm{L}$ (figure 1).

\section{DISCUSSION}

We aimed to examine the association between serum triglycerides and serum cholesterol and the risk of developing heart failure in healthy women as the question has not been thoroughly investigated. In the present study, we could longitudinally follow three cohorts of 50-year-old women; the earliest cohort was followed for 44 years and the latest cohort was followed for 20 years. There was a significant association between fasting serum triglyceride values at baseline at the age of 50 and later heart failure, but not for serum cholesterol, when analysing all three cohorts together, as well as when analysing the cohort born in 1918 separately.

A strength of the study is the high participation rate and representativeness of the women. Another strength is the long follow-up time (44 years for the cohort born in 1918), which is an essential requirement for heart failure studies.

There are limitations of the study, and one of them is the fairly small number of women in each cohort. Nevertheless, we found that serum triglycerides were significantly and independently associated with a higher risk of heart failure development over time.

An additional limitation is that more advanced analyses of lipids such as s-HDL-cholesterol, serum low-density lipoprotein cholesterol (s-LDL-cholesterol) or apolipoprotein were not available at the time.

Earlier studies showed that low levels of total cholesterol and triglycerides predicted a worse prognosis than high levels in patients with established heart failure. ${ }^{12} 24$ One explanation for this may be that lower levels of s-triglycerides and s-cholesterol may be an expression for a more advanced stage of heart failure or a malnourished 

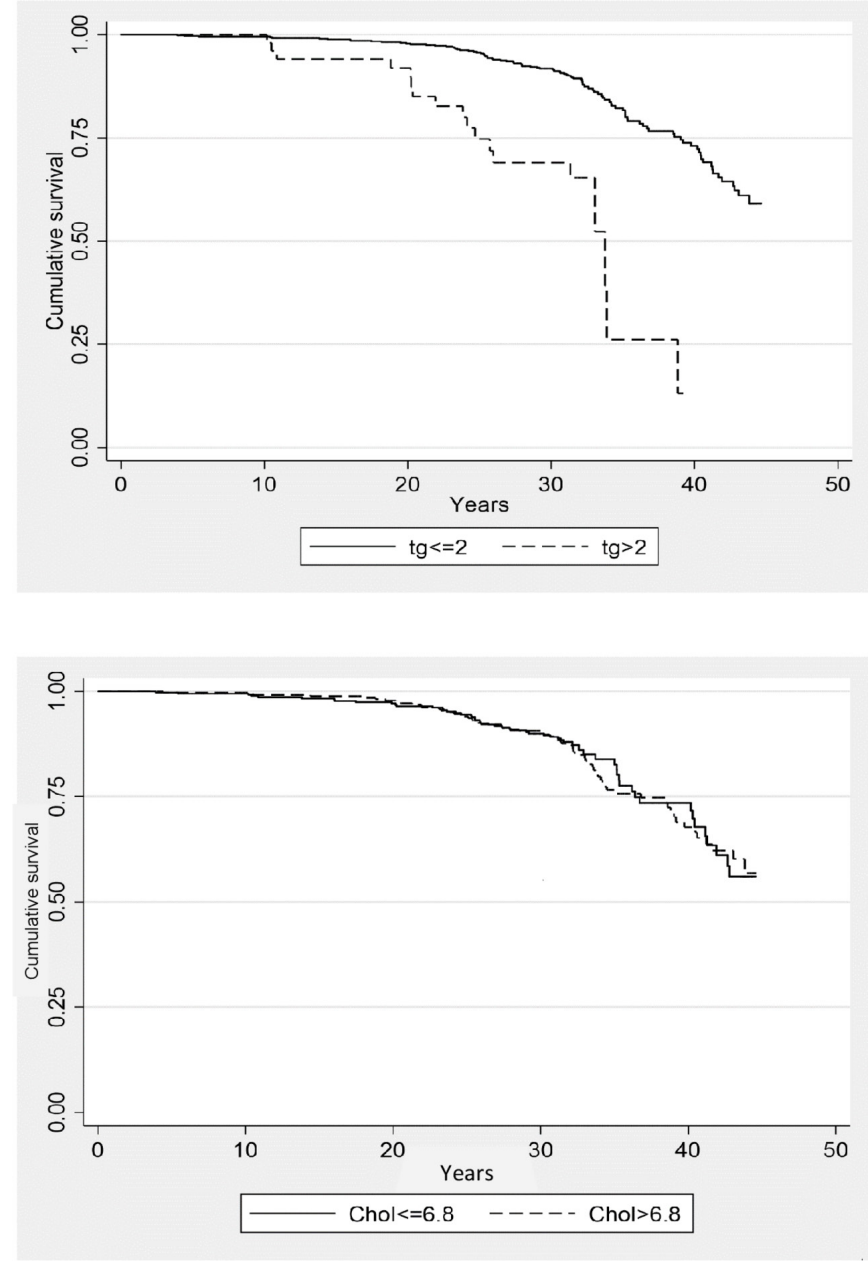

Figure 1 Estimated cumulative survival by Kaplan-Meier survival plot of the women in the examinations 1968 and 1980 with a cut-off level of serum triglycerides at $2.0 \mathrm{mmol} / \mathrm{L}$, and a cut-off level of serum cholesterol at $6.8 \mathrm{mmol} / \mathrm{L}$. Chol, cholesterol; tg, triglycerides.

patient, as in cardiac cachexia, who is more likely to have a worse prognosis compared with healthier individuals. It has also been proposed that high levels of cholesterol in chronic heart failure are beneficial because of the capacity of circulating cholesterol-rich lipoproteins to bind and inactivate endotoxin which otherwise is a very strong stimulator for the release of inflammatory cytokines from circulating immune competent cells and may cause substantial immune activation in patients with heart failure. ${ }^{25}$ A low serum triglyceride level $(<150 \mathrm{mg}$ / $\mathrm{dL},<1.7 \mathrm{mmol} / \mathrm{L}$ ) was an independent predictor of cardiovascular death in women but not in men with chronic heart failure. ${ }^{26}$ These studies were conducted on patients already diagnosed with heart failure, but there is a possibility that these findings do not apply to individuals without heart failure. On the contrary, in our study, it appears that high serum triglycerides, but not serum cholesterol, increase the risk of future heart failure, which is in accordance with another prospective observational study based on two population studies in Denmark showing that stepwise higher concentrations of non-fasting serum triglycerides were related to increased risk of heart failure, whereas high levels of LDL-cholesterol did not affect the risk of heart failure.$^{27}$ Increased levels of s-LDLcholesterol are a known very strong factor for development of atherosclerotic coronary heart disease, which in young middle-aged men more often than in young middle-aged women, lead to obstructive coronary artery disease ${ }^{28}$ often proceeding to acute coronary syndrome with myocardial infarction resulting in heart failure with reduced ejection fraction. Lowering LDL-cholesterol has proven beneficial for reducing major cardiac coronary events in both men and women. A meta-analysis of 27 trials of statin therapy reported equal proportional reduction for men and women in major coronary events (nonfatal myocardial infarction or coronary death) for each reduction of $1.0 \mathrm{mmol} / \mathrm{L}$ in LDL-cholesterol. ${ }^{29}$ However, women with acute coronary syndrome more often than men present with non-obstructive coronary artery disease and more prevalently with coronary microvascular disease. $^{30-32}$ Coronary microvascular disease is closely related to systemic low-grade inflammation which in turn is closely linked to heart failure with preserved ejection fraction, which is the most predominant phenotype of heart failure in women. ${ }^{33-35}$ Patients with familial hypercholesterolaemia have high levels of LDL-cholesterol and an increased risk of coronary artery disease. One study reported that in this group of patients there was an increased risk of heart failure in both men and women and most of the patients had coronary artery disease and nearly $40 \%$ had suffered from myocardial infarction. ${ }^{36}$ One hypothesis may be that LDL-cholesterol predominantly causes epicardial artery dysfunction and promotes atherosclerosis in larger coronary arteries, but does not affect the microvascular coronary circulation to the same extent. ${ }^{37}$ On the other hand, serum triglycerides are associated with inflammation, ${ }^{38}$ and may thereby affect coronary microvascular circulation and thus influence the risk of heart failure as well as contribute to the epicardial atherosclerotic process. High levels of triglycerides are also associated with overweight/obesity and diabetes which are known risk factors for ischaemic heart disease and myocardial infarction frequently leading to heart failure with reduced ejection fraction. Our study showed that increasing levels of fasting serum triglycerides were significantly associated with increased risk of developing heart failure in the women in the oldest cohort. We could not show an increased risk of heart failure in the younger cohort, which may reflect the different follow-up times for the both cohorts, and possibly the slightly smaller sample size for the younger cohort and also differences in baseline between the cohorts. We could not show any significant association between serum cholesterol and the risk of later heart failure in any of the cohorts separately. When the three cohorts were analysed together, the results remained strong, showing significant association between serum triglycerides and increased risk of heart failure, but no significant association between serum cholesterol and future heart failure. In the light 
of these results, it is encouraging that there are evidence of secular trends showing lower levels of triglycerides in 38-year-old and 50-year-old women over time in Sweden. ${ }^{20}$

However, the lack of any significant association whatsoever between serum cholesterol level and future risk of heart failure in 50-year-old women with a follow-up duration of at least 20 years should merit careful consideration and re-evaluation of indications for cholesterol reducing drugs as heart failure risk factor primary prevention treatment for young and middle-aged women. Heart failure and stroke are the predominant cardiovascular diseases in women, in contrast to men, where myocardial infarction is predominant.

\section{CONCLUSIONS}

High serum triglycerides but not serum cholesterol in 50-year-old women are associated with increased risk of later heart failure and may thus be considered a risk marker for later development of heart failure. Support of lifestyle changes should be the initial heart failure preventive approach.

\section{Author affiliations}

${ }^{1}$ Primary Health Care, School of Public Health and Community Medicine, Institute of Medicine, Sahlgrenska Academy, University of Gothenburg, Goteborg, Sweden ${ }^{2}$ School of Public Health and Community Medicine, Institute of Medicine, Sahlgrenska Academy, University of Gothenburg, Goteborg, Sweden ${ }^{3}$ Molecular and Clinical Medicine, Institute of Medicine, Sahlgrenska Academy, University of Gothenburg, Goteborg, Sweden

Contributors All authors participated in the planning of the study, monitored data, drafted and revised the paper. All authors had full access to all of the study data and take responsibility for the integrity and accuracy of the data. All authors have read and approved the final version of the paper. Guarantor of the article CB accepts full responsibility for the work and the conduct of the study, had access to the data and controlled the decision to publish.

Funding This work was supported by grants from the Swedish Council for Health, Working Life and Welfare-FORTE (EpiLife 2006-1506, WISH 2007-1958) and by grants from the Swedish state under the agreement between the Swedish government and the country councils, the ALF-agreement (68771 and 30411).

Disclaimer The study sponsors had no role in the study design; in the collection, analysis and interpretation of data; in the writing of the report; and in the decision to submit the article for publication. The researchers were independent from funders. All authors had full access to all of the data (including statistical reports and tables) in the study and can take responsibility for the integrity of the data and the accuracy of the data analysis.

Competing interests None declared.

Patient and public involvement Patients and/or the public were not involved in the design, or conduct, or reporting, or dissemination plans of this research.

\section{Patient consent for publication Not required.}

Ethics approval Ethics approval for the study has been obtained from the ethical review board of Gothenburg University/Regional ethical review board, diary no 65-80, 179-92, 0̈ 402-99, T 257-00. The participants gave informed consent before taking part. The guarantor of the manuscript (last author) affirms that the manuscript is an honest, accurate and transparent account of the study being reported; that no important aspects of the study have been omitted; and that any discrepancies from the study as originally planned have been explained.

Provenance and peer review Not commissioned; externally peer reviewed.

Data availability statement Data are available upon reasonable request. The datasets generated during and/or analysed during the current study are not publicly available due to Swedish law, but are available from the corresponding author on reasonable request.
Open access This is an open access article distributed in accordance with the Creative Commons Attribution Non Commercial (CC BY-NC 4.0) license, which permits others to distribute, remix, adapt, build upon this work non-commercially, and license their derivative works on different terms, provided the original work is properly cited, appropriate credit is given, any changes made indicated, and the use is non-commercial. See: http://creativecommons.org/licenses/by-nc/4.0/.

ORCID iDs

Anna-Karin Halldin http://orcid.org/0000-0001-7821-2538

Cecilia Björkelund http://orcid.org/0000-0003-4083-7342

\section{REFERENCES}

1 Leto L, Feola M. Cognitive impairment in heart failure patients. $J$ Geriatr Cardiol 2014;11:316-28.

2 Ambrosy AP, Fonarow GC, Butler J, et al. The global health and economic burden of hospitalizations for heart failure: lessons learned from hospitalized heart failure registries. J Am Coll Cardiol 2014;63:1123-33.

3 Cook C, Cole G, Asaria P, et al. The annual global economic burden of heart failure. Int J Cardiol 2014;171:368-76.

4 Stewart S, Maclntyre K, Hole DJ, et al. More 'malignant' than cancer? Five-year survival following a first admission for heart failure. Eur J Heart Fail 2001;3:315-22.

5 Mosterd A, Hoes AW. Clinical epidemiology of heart failure. Heart 2007;93:1137-46.

6 Zarrinkoub R, Wettermark B, Wändell P, et al. The epidemiology of heart failure, based on data for 2.1 million inhabitants in Sweden. Eur $J$ Heart Fail 2013;15:995-1002.

7 Heidenreich PA, Albert NM, Allen LA, et al. Forecasting the impact of heart failure in the United States: a policy statement from the American heart association. Circ Heart Fail 2013;6:606-19.

8 Redfield MM, Jacobsen SJ, Burnett JC, et al. Burden of systolic and diastolic ventricular dysfunction in the community: appreciating the scope of the heart failure epidemic. JAMA 2003;289:194-202.

9 Nieminen MS, Harjola V-P, Hochadel M, et al. Gender related differences in patients presenting with acute heart failure. results from EuroHeart failure survey II. Eur J Heart Fail 2008;10:140-8.

10 Halldin A-K, Schaufelberger M, Lernfelt B, et al. Obesity in middle age increases risk of later heart failure in Women-Results from the prospective population study of women and $\mathrm{H} 70$ studies in Gothenburg, Sweden. J Card Fail 2017;23:363-9.

$11 \mathrm{He}$ J, Ogden LG, Bazzano LA, et al. Risk factors for congestive heart failure in US men and women: NHANES I epidemiologic follow-up study. Arch Intern Med 2001;161:996-1002.

12 Freitas HFG, Barbosa EA, Rosa FHFP, et al. Association of HDL cholesterol and triglycerides with mortality in patients with heart failure. Braz J Med Biol Res 2009;42:420-5.

13 Velagaleti RS, Massaro J, Vasan RS, et al. Relations of lipid concentrations to heart failure incidence: the Framingham heart study. Circulation 2009;120:2345-51.

14 Ingelsson E, Arnlöv J, Sundström J, et al. Novel metabolic risk factors for heart failure. J Am Coll Cardiol 2005;46:2054-60.

15 Ingelsson E, Arnlöv J, Lind L, et al. Metabolic syndrome and risk for heart failure in middle-aged men. Heart 2006;92:1409-13.

16 Holme I, Aastveit AH, Hammar N, et al. Lipoprotein components and risk of congestive heart failure in 84,740 men and women in the apolipoprotein mortality risk study (AMORIS). Eur $J$ Heart Fail 2009;11:1036-42.

17 Bengtsson C, Blohmé G, Hallberg L, et al. The study of women in Gothenburg 1968-1969--a population study. General design, purpose and sampling results. Acta Med Scand 1973;193:311-8.

18 Bengtsson C, Gredmark T, Hallberg L, et al. The population study of women in Gothenburg 1980-81--the third phase of a longitudinal study. Comparison between participants and non-participants. Scand J Soc Med 1989;17:141-5.

19 Bengtsson C, Ahlqwist M, Andersson K, et al. The prospective population study of women in Gothenburg, Sweden, 1968-69 to 1992-93. A 24-year follow-up study with special reference to participation, representativeness, and mortality. Scand J Prim Health Care 1997;15:214-9.

20 Björkelund C, Andersson-Hange D, Andersson K, et al. Secular trends in cardiovascular risk factors with a 36 -year perspective: observations from 38- and 50-year-olds in the population study of women in Gothenburg. Scand J Prim Health Care 2008;26:140-6.

21 Carlsson G. Social mobility and class structure. Lund: CWK Gleerup, 1958.

22 Grimby G, Börjesson M, Jonsdottir IH, et al. The "Saltin-Grimby Physical Activity Level Scale" and its application to health research. Scand J Med Sci Sports 2015;25:119-25. 
23 Ingelsson E, Arnlöv J, Sundström J, et al. The validity of a diagnosis of heart failure in a hospital discharge register. Eur $J$ Heart Fail 2005;7:787-91.

24 Greene SJ, Vaduganathan M, Lupi L, et al. Prognostic significance of serum total cholesterol and triglyceride levels in patients hospitalized for heart failure with reduced ejection fraction (from the Everest trial). Am J Cardiol 2013;111:574-81.

25 Rauchhaus M, Coats AJ, Anker SD. The endotoxin-lipoprotein hypothesis. Lancet 2000;356:930-3.

26 Kozdag G, Ertas G, Emre E, et al. Low serum triglyceride levels as predictors of cardiac death in heart failure patients. Tex Heart Inst J 2013;40:521-8.

27 Varbo A, Nordestgaard BG. Nonfasting Triglycerides, Low-Density Lipoprotein Cholesterol, and Heart Failure Risk: Two Cohort Studies of 113554 Individuals. Arterioscler Thromb Vasc Biol 2018;38:464-72.

28 Chiha J, Mitchell P, Gopinath B, et al. Gender differences in the severity and extent of coronary artery disease. Int $J$ Cardiol Heart Vasc 2015;8:161-6.

29 , Fulcher J, O'Connell R, Cholesterol Treatment Trialists' (CTT) Collaboration, et al. Efficacy and safety of LDL-lowering therapy among men and women: meta-analysis of individual data from 174,000 participants in 27 randomised trials. Lancet 2015;385:1397-405.

30 Reis SE, Holubkov R, Conrad Smith AJ, et al. Coronary microvascular dysfunction is highly prevalent in women with chest pain in the absence of coronary artery disease: results from the NHLBI wise study. Am Heart J 2001;141:735-41.

31 Shaw LJ, Bugiardini R, Merz CNB. Women and ischemic heart disease: evolving knowledge. J Am Coll Cardiol 2009;54:1561-75.
32 Anderson RD, Petersen JW, Mehta PK, et al. Prevalence of coronary endothelial and microvascular dysfunction in women with symptoms of ischemia and NO obstructive coronary artery disease is confirmed by a new cohort: the NHLBI-Sponsored women's ischemia syndrome Evaluation-Coronary vascular dysfunction (WISE-CVD). J Interv Cardiol 2019;7169275.

33 Taqueti VR, Solomon SD, Shah AM, et al. Coronary microvascular dysfunction and future risk of heart failure with preserved ejection fraction. Eur Heart J 2018;39:840-9.

34 Shah SJ, Lam CSP, Svedlund S, et al. Prevalence and correlates of coronary microvascular dysfunction in heart failure with preserved ejection fraction: PROMIS-HFpEF. Eur Heart J 2018;39:3439-50.

35 Lenzen MJ, Scholte op Reimer WJM, Boersma E, et al. Differences between patients with a preserved and a depressed left ventricular function: a report from the EuroHeart failure survey. Eur Heart $J$ 2004;25:1214-20.

36 Hovland A, Mundal LJ, Igland J, et al. Increased risk of heart failure and atrial fibrillation in heterozygous familial hypercholesterolemia. Atherosclerosis 2017;266:69-73.

37 Ford MA, McConnell JP, Lavi S, et al. Coronary artery endothelial dysfunction is positively correlated with low density lipoprotein and inversely correlated with high density lipoprotein subclass particles measured by nuclear magnetic resonance spectroscopy. Atherosclerosis 2009;207:111-5.

38 Welty FK, Welty Francine K. How do elevated triglycerides and low HDL-cholesterol affect inflammation and atherothrombosis? Curr Cardiol Rep 2013;15:400. 